\title{
Preface
}

\section{International Congress on Vascular Dementia, Athens, Greece, 17-20 October 2013}

The International Congress on Vascular Dementia takes place biennially in different sites across Europe. The 2013 congress took place in Athens, Greece, attracting 464 participants. The congress again featured the utmost topics of interest as well as new developments in the field, with a very exhaustive program. (The program may still be viewed at http://www2.kenes.com/vascular/sci/Pages/Scientific $\% 20$ Program.aspx). For the first time, the meeting was held under joint auspices with the World Federation of Neurology Research Group on Dementia, and the Chair of the group, Professor Raul Arizaga, was heavily involved in the organization and selection of topics and speakers of the Congress.

The congress was also endorsed by Alzheimer Hellas, the Greek affiliate of Alzheimer's Disease International.

Several of the presentations at the congress were submitted for publication in this Supplementary Issue of the Journal of Alzheimer's Disease (JAD), and following a strict review process, we have accepted 33 manuscripts. The topics are of course heterogeneous, covering the clinical manifestations and the pathophysiological basis of dementia in general and the vascular components leading to it, the underlying pathology and the development of imaging, including magnetic resonance imaging as well as visualization of the blood vessels and blood flow, and, of course, the advances in the development of new interventions using pharmacological and non-drug approaches.

We all recognize today that pure vascular dementia is very rare and most demented individuals have multiple pathologies, differing in proportion in different individuals. These vascular changes are also heterogeneous in their etiology, distribution, and in their temporal evolution. The affected brains also differ in their structure (i.e., hardware) and evolution (i.e., software), as well as in their abilities to compensate and correct the lesions. As a consequence of that, the cognitive changes differ and are unique to each individual. A central research goal is therefore to understand these different factors in order to be able to manipulate them and reduce, or correct, the damage.

All these issues, and more, were discussed in Athens and the progress made was presented. There is a lot more ground to cover, some of which will be demonstrated at the next congress which will take place in Paris, France in October 2015.

Professor Emeritus Amos D. Korczyn Tel-Aviv University Medical School Ramat Aviv 69978, Israel

Tel.: +972 36974229

Fax: +972 36973472

E-mail: amoskor@tau.ac.il 